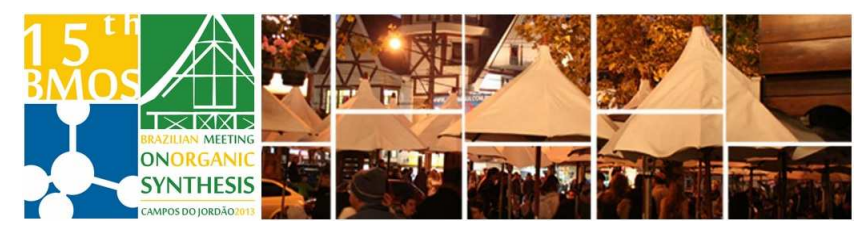

\title{
Synthesis of new hemilabile ligands based on phosphinic amide and pyrazolo[1,5-c]quanazoline moieties Applications in coordination chemistry
}

\author{
Roberta K. F. Marra', Alice M. R. Bernardino', Marcos C. de Souza', Gilberto A. \\ Romeiro $^{1}$, María J. Iglesias ${ }^{2}$, Fernando López-Ortiz ${ }^{* 2}$ \\ ${ }^{1}$ Departamento de Química Orgânica, Instituto de Química, Universidade Federal Fluminense, Outeiro de \\ São João Baptitsa, cep 24020-141, Niterói, RJ, Brasil. ${ }^{2}$ Área de Química Orgánica, universidad de Almería, \\ Carretera de Sacramento s/n, Almería, Spain? \\ *flortiz@ual.es
}

Keywords: Pyrazol, Phosphinic Amide, Complex.

\section{INTRODUCTION}

We have previously shown that bis(phosphinic amide)-phosphine oxides can be accessed via directed ortho lithiation (DoM) of phosphinic amides. ${ }^{1}$ The tridentate ligand was the basis for the development of membrane and optical fiber luminescence sensors. ${ }^{2}$ We envisaged that this methodology could be extended to the synthesis of new hemilabile $\mathrm{O}, \mathrm{N}$-chelating ligands. Here we describe the preparation of pirazoloquinazolinephosphinic amide ligands through condensation of o-formylphosphinic amides with 2-pyrazolylanilines followed by oxidation and their complexation behavior towards zinc salts.

\section{RESULTS AND DISCUSSION}

Pyrazolo[1,5-c]quinazoline-phosphinic amides (5a-e) were synthesized in a three step process consisting of $o$-formylation of diphenylphosphinic amide (1), condensation with 2-pyrazolylanilines (2) catalyzed by $\mathrm{ZnCl}_{2}$ and oxidation of the resulting dihydropyrazoloquinolines (4a-e) using 2,3-dichloro-5,6dicyanobenzoquinone (DDQ), to the desired products (5) (Scheme 1).

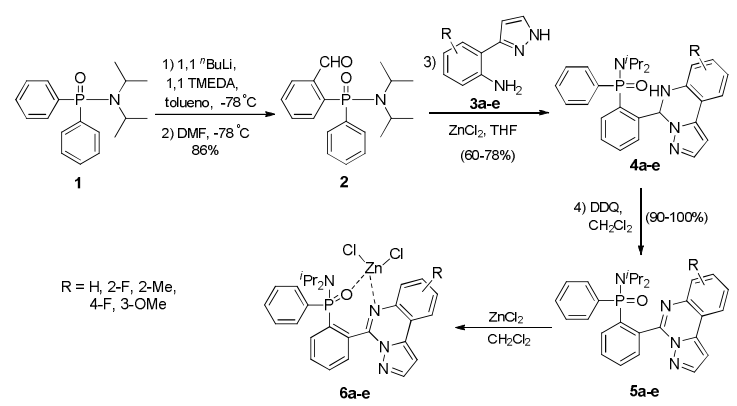

Scheme 1. Synthetic route to Pyrazolo[1,5-c]quinazolinephosphinic (5a-e) and their Zn(II) complexes (6a-e).
All new compounds were characterized by HR-MS, IR, ${ }^{1} \mathrm{H},{ }^{13} \mathrm{C}$ and ${ }^{31} \mathrm{P}$ NMR spectroscopy. The metalbinding abilities of compounds (5) towards $\mathrm{Zn}(\mathrm{II})$ cations were investigated. Preliminary results indicate that coordination to the metal cation takes place through the oxygen of the phosphinic amide and the nitrogen of the quinazoline moiety.

\section{CONCLUSION}

An efficient methodology for the synthesis of pyrazolo[1,5-c]quinazoline-phosphinic amides (5a-e) has been developed. They behave as $\mathrm{O}, \mathrm{N}$-chelating ligands towards zinc dichloride through formation of seven-membered $\mathrm{N}-\mathrm{Zn}-\mathrm{O}$ metallacycles (6a-e). Further applications of the ligands in catalysis are currently under investigation in our laboratory.

\section{ACKNOWLEDGEMENTS}

We thank the MEC and FEDER program for financial support (project CTQ2011-27705) and the Programa Hispano-Brasileño de Cooperación Interuniversitaria for researcher's mobility funding (project HBP-2011-0158).

\section{REFERENCES}

${ }^{1}$ Popovici, C.; Fernández, I.; Oña-Burgos, P.; Roces, L.; García-GrandaS.; López-Ortiz, F. Dalton Trans. 2011, 40,6691.

2 (a) Sainz-Gonzalo, F. J.; Casimiro, M.; Popovici, C.; Rodríguez-Diéguez, A.; Fernández-Sánchez, J. F.; Fernández, I. López-Ortiz, F.; FernándezGutiérrez A. Dalton Trans. 2012, 41, 6735. (b) Sainz-Gonzalo, F. J.; Elosua, C.; Fernández-Sánchez, J. F.; Popovici, C.; Fernández, I.; Ortiz, F. L.; Arregui, F. J.; Matias, I. R.; Fernández-Gutiérrez, A. Sensor. Actuat. BChem. 2012, 173, 254. 